\title{
Spectrum of dominant mutations in the desmosomal cadherin desmoglein 1, causing the skin disease striate palmoplantar keratoderma
}

\author{
Debbie M Hunt ${ }^{1}$, Lisa Rickman ${ }^{1}$, Neil V Whittock ${ }^{2}$, Robin AJ Eady ${ }^{2}$, Danijela Šimrak ${ }^{1,3}$, \\ Patricia JC Dopping-Hepenstal ${ }^{2}$, Howard P Stevens ${ }^{4}$, D Keith B Armstrong ${ }^{5}$, \\ Hans Christian Hennies ${ }^{6}$, Wolfgang Küster ${ }^{7}$, Anne E Hughes ${ }^{5}$, Joachim Arnemann ${ }^{3}$, \\ Irene M Leigh ${ }^{4}$, John A McGrath ${ }^{2}$, David P Kelsell ${ }^{4}$ and Roger S Buxton*,1
}

\begin{abstract}
${ }^{1}$ Division of Membrane Biology, National Institute for Medical Research, Mill Hill, London, NW7 1AA, UK; ${ }^{2}$ Department of Cell and Molecular Pathology, St. John's Institute of Dermatology, Guy's, King's and St. Thomas' Hospitals' School of Medicine, St. Thomas' Hospital, London, SE1 7EH, UK; ${ }^{3}$ Klinikum der Johann Wolfgang Goethe-Universität, Institut für Humangenetik, Theodor-Stern-Kai 7 - Haus 9, D-60590 Frankfurt am Main 70, Germany; ${ }^{4}$ Centre for Cutaneous Research, St. Bartholomew's \& The Royal London School of Medicine \& Dentistry, Queen Mary \& Westfield College, Clinical Sciences Research Building, 2 Newark Street, London E1 2AT, UK; ${ }^{5}$ Department of Medical Genetics, The Queen's University of Belfast, Belfast City Hospital, Belfast BT9 7AB, UK; ${ }^{6}$ Department of Molecular Genetics and Gene Mapping Centre, Max-Delbrück-Centrum Berlin-Buch, RobertRoessle-Str. 10, 13092 Berlin, Germany; ${ }^{7}$ TOMESA-Fachklinik, Riedstr. 18 36361, Bad Salzschlirf, Germany
\end{abstract}

The adhesive proteins of the desmosome type of cell junction consist of two types of cadherin found exclusively in that structure, the desmogleins and desmocollins, coded by two closely linked loci on human chromosome 18q12.1. Recently we have identified a mutation in the DSG1 gene coding for desmoglein 1 as the cause of the autosomal dominant skin disease striate palmoplantar keratoderma (SPPK) in which affected individuals have marked hyperkeratotic bands on the palms and soles. In the present study we present the complete exon-intron structure of the DSG1 gene, which occupies approximately $\mathbf{4 3} \mathbf{~ k b}$, and intron primers sufficient to amplify all the exons. Using these we have analysed the mutational changes in this gene in five further cases of SPPK. All were heterozygotic mutations in the extracellular domain leading to a truncated protein, due either to an addition or deletion of a single base, or a base change resulting in a stop codon. Three mutations were in exon 9 and one in exon 11, both of which code for part of the third and fourth extracellular domains, and one was in exon 2 coding for part of the prosequence of this processed protein. This latter mutation thus results in the mutant allele synthesising only 25 amino acid residues of the prosequence of the protein so that this is effectively a null mutation implying that dominance in the case of this mutation was caused by haploinsufficiency. The most severe consequences of SPPK mutations are in regions of the body where pressure and abrasion are greatest and where desmosome function is most necessary. SPPK therefore provides a very sensitive measure of desmosomal function. European Journal of Human Genetics (2001) 9, $197-203$.

Keywords: desmosome; cadherin; desmoglein; dominance; epidermis; keratoderma

\footnotetext{
*Correspondence: Dr Roger S Buxton, Division of Membrane Biology, National Institute for Medical Research, The Ridgeway, Mill Hill, London NW7 1AA, UK. Tel: +44 2089593666 ext. 2225;

Fax: +44 208906 4477; E-mail: rbuxton@nimr.mrc.ac.uk

Received 29 May 2000; revised 27 October 2000; accepted 1 November 2000
} 


\section{Introduction}

Desmosomes are specialised junctional complexes that form sites of cell-cell adhesion between epithelial cells, and contact with the internal intermediate filament network. ${ }^{1,2}$ They consist of the transmembrane cell adhesion proteins, the desmogleins (DSG) and desmocollins (DSC), members of the cadherin superfamily, and the constitutive cytoplasmic plaque proteins, desmoplakin and plakoglobin and various accessory proteins such as plakophilins 1,2 and $3^{3}$ which are involved in the linkage with the intermediate filaments.

The way in which such specialised junctions are fabricated is of great interest in cell biology. Striate palmoplantar keratoderma (SPPK; MIM 148700) is one of a group of skin diseases where there is thickening of the skin on the palms and soles, ${ }^{4,5}$ this particular disease being characterised by longitudinal hyperkeratotic lesions on the palms, running the length of each finger. Two types of SPPK have been reported to date, one mapping to chromosome $18 \mathrm{q} 12.1^{6}$ where the desmosomal cadherins map $^{7}$ and one on $6 \mathrm{p} 21^{8}$ where the desmoplakin gene is found, ${ }^{7}$ and mutations have been found in both the desmoplakin gene, ${ }^{8,9}$ and in a desmosomal cadherin, desmoglein. ${ }^{10}$ It is thought that in this disease, incorrect desmosomal function results in hyperkeratotic lesions in those regions of the body where desmosome function is most necessary. Thus, in these admittedly mild skin diseases, the lesions occur on the hands and feet, and are exacerbated by, for example manual labour. This disease therefore provides a very sensitive measure of desmosomal function. In the case of SPPK caused by a mutation in desmoplakin, the evidence presented suggested that dominance was caused by haploinsufficiency since only the wild-type allele was expressed in mutant tissue; thus expression of only the haploid complement of the desmoplakin gene gave rise to the clinical symptoms of SPPK. It is not yet clear however whether gene dosage is critical for correct desmoglein 1 expression since in the case of the DSG1 SPPK mutation, mRNA coding for the mutant protein deleted at the amino terminus was still synthesised.

In the present study we have searched for further SPPK mutations in the DSG1 gene coding for desmoglein 1 in order to determine the spectrum of mutations and to try to gain insight into whether diploid gene expression of this cell adhesion protein is necessary for correct desmosomal function.

\section{Materials and methods Subjects}

Case B was examined by WK, ${ }^{11}$ cases $\mathrm{C}$ and D by HPS (who previously examined case $\mathrm{A}^{10}$ ), case $\mathrm{E}$ by DKBA and case $\mathrm{F}$ by JAM. Genomic DNA was isolated from peripheral blood collected in EDTA-containing tubes according to standard techniques. $^{12}$ All samples were collected after informed consent had been obtained and in accordance with the local institutional review board. By light microscopy the overall architecture of the epidermis was retained but there was a modest increase in the number of nucleated cell layers and a massive increase (about four times normal) in the thickness of the stratum corneum. There was no obvious widening of the intercellular spaces in the epidermis or other changes which might suggest a loss of cell-cell adhesion.

\section{Exon-intron boundary determination}

Exon-exon PCR was performed with high molecular weight genomic DNA or PAC DNA (clone 159P13 ${ }^{13}$ ) containing the DSG1 gene; in these cases the PCR product from the clone which was sequenced was the same size as that derived from genomic DNA. PCR was performed using standard conditions $^{7}$ with consecutive forward and reverse exon primer pairs so that the whole cDNA was covered, using AmpliTaq DNA polymerase (Perkin-Elmer) with extension times up to $5 \mathrm{~min}$ at $72^{\circ} \mathrm{C}$ and 1 unit of Perfect Match (Stratagene) per $50 \mu \mathrm{l}$ reaction. For longer PCR the Expand Long Template PCR System (Roche) was used. The PCR products were cloned using either the TA cloning kit into pCRII (Invitrogen Corp., San Diego, CA, USA) or the pMOSBlue T-vector kit (Amersham International plc., Amersham, UK) and sequenced.

\section{Mutation analysis}

Sequence derived from PCR amplified introns was used to design intron primers that could be used to amplify each exon together with a small amount of intron. To screen for mutations in the DSG1 gene, exons and splice junctions were amplified by PCR from genomic DNA using the primers shown in Table 2 and sequenced directly in an ABI 377 Automated Sequencer using the Perkin-Elmer BigDye Terminator Cycle Sequencing kit, after purification in Centrisep spin columns (Princeton Separations). Electropherograms were examined manually to identify regions of heterozygosity. Exons with potential heterozygotes were amplified by PCR and at least six clones obtained using TA cloning methods (Invitrogen), which were then sequenced.

\section{Results}

Exon-intron structure of the DSG1 gene

Using primers from the DSG1 cDNA sequence ${ }^{14}$ in PCR on genomic DNA, we cloned all of the exons and introns, and sequenced the exon-intron boundaries (Table 1) and sufficient intron sequence to generate intron primers (Table 2). Intron position is remarkably conserved amongst the classical cadherins ${ }^{15-17}$ and in the extracellular domain of the desmogleins (bovine DSG $1^{18}$ and human DSG ${ }^{19}$ ) and the desmocollins (human DSC $2^{20}$ ) and DSG1 is no exception, the position of the introns being completely conserved compared with those of bovine DSG1 even where the amino acids are different. ${ }^{18}$ As noted for many other genes the sizes of the introns varies considerably from those in the bovine gene. The whole gene occupies about $43 \mathrm{~kb}$ (Figure 1). 
Table 1 Sequences flanking the intron/exon boundaries of the human DSG1 gene

\begin{tabular}{|c|c|c|c|c|}
\hline Exon & Exon size (bp) & $5^{\prime}$ splice donor ${ }^{a}$ & Intron size $(\mathrm{kb})$ & 3' splice acceptor \\
\hline 2 & 36 & (R-I-Q - 22) CGA-ATC-CAG gtaatat & 0.257 & tcatttaag GTA-AGA-GAT (-21 V-R-D) \\
\hline 3 & 132 & (I-A-K 23) ATC-GCC-AAA gtaggtat & 1.4 & ttctgcag ATT-CAC-TCA (24 I-H-S) \\
\hline 5 & 145 & (S-N-A-N 124) TCT-AAT-GCA-A gtaagtaatg & 1.89 & ttttctag AT-ACA-CTG (124 N-T-L) \\
\hline 6 & 167 & (D-R-E 179) GAC-AGA-GAG gtaattc & 1.7 & attttttag CAA-TAC-GGC (180 Q-Y-G) \\
\hline 7 & 135 & (Q-S-S 224) CAG-TCT-TCA gtaag & 0.72 & gtttcag TAT-ACC-ATA (225 Y-T-I) \\
\hline 10 & 140 & (S-I-D-D 420) TCT-ATA-GAT-G gtaag & 1.38 & attacag AT-AAT-CTT-CAA (420 D-N-L-Q) \\
\hline 11 & 282 & (V-L-G-L 514) GTC-TTA-GGA-T gtaagtac & 3.65 & caccag TG-GTC-CCA-TTT (514 L-V-P-F) \\
\hline 12 & 134 & (E-P-R 558) GAA-CCC-AGG gtaagtgc & 0.69 & tcttttag GAT-ATA-AGC (559 D-I-T) \\
\hline 13 & 70 & (D-N-S-G 582) GAC-AAC-TCA-G gtaagaa & 2.01 & cttttag GA-GTT-TAT-ACA (582 G-V-Y-T) \\
\hline 14 & 209 & (F-C-Q 651) TTC-TGT-CAG gtaaggtcce & $\sim 12.3$ & ctataaattcag AAA-GCA-TAT (652 K-A-Y) \\
\hline 15 & 1047+noncoding & & & \\
\hline
\end{tabular}

${ }^{a}$ The exon sequences are shown in capital letters, while the intron sequences are in lower case letters. The exon size in base pairs (bp) and the estimated size of the introns in kilobases $(\mathrm{kb})$ are indicated. The letters and numbers in brackets indicate the amino acid residues flanking the exon boundaries.

Table 2 Primers to amplify exons of human DSG1

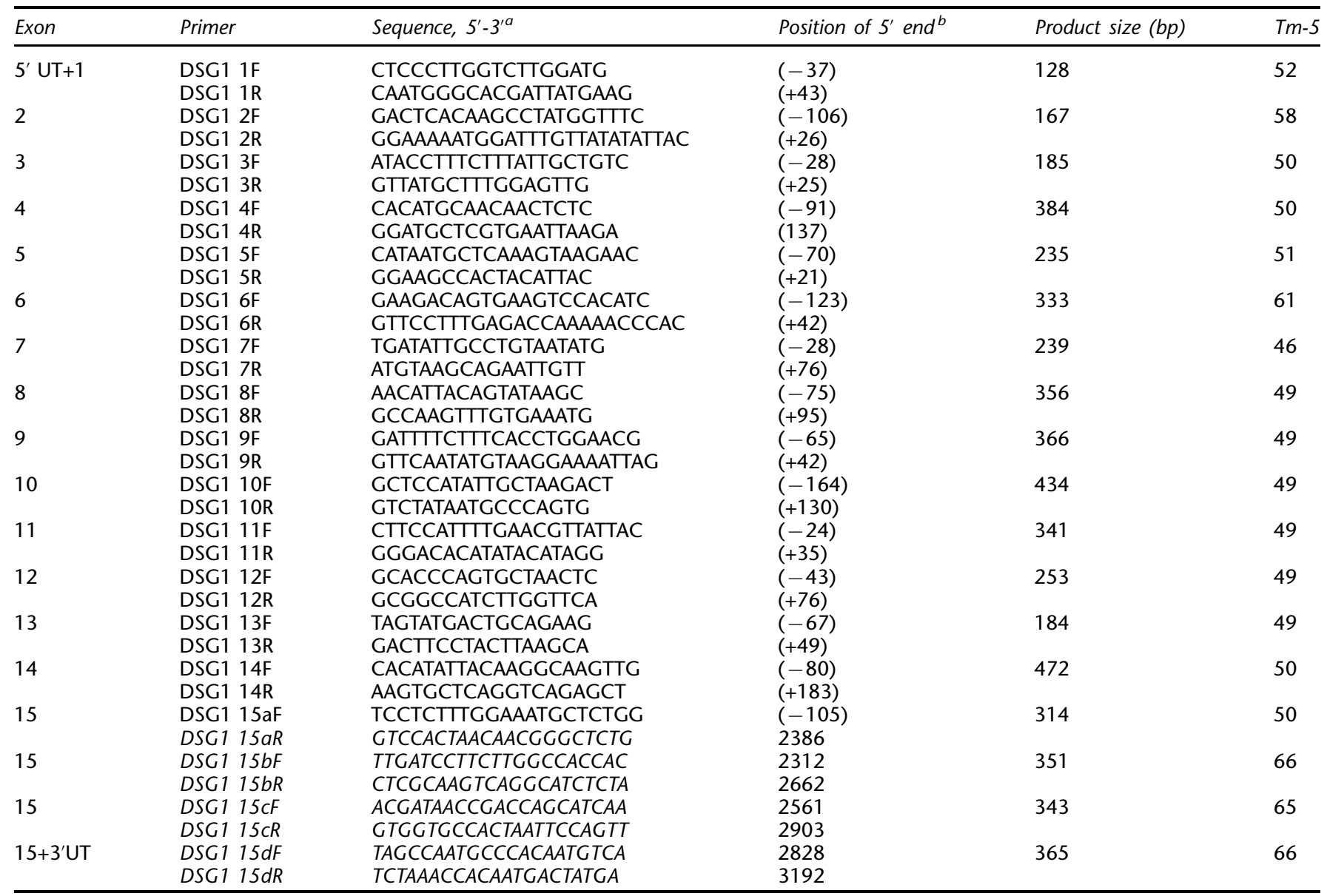

antron primers in normal type, exon primers in italic. ${ }^{b}$ Numbers in brackets are in introns or 5 'UT and numbered from the adjacent exon. Numbers not in brackets are in CDNA sequence (EMBL X56654) in which the ATG coding for methionine at nt 78 in the sequence ATGGACTGG is presumed to be in the initiation codon, with the first nucleotide of this ATG codon as 1 . 


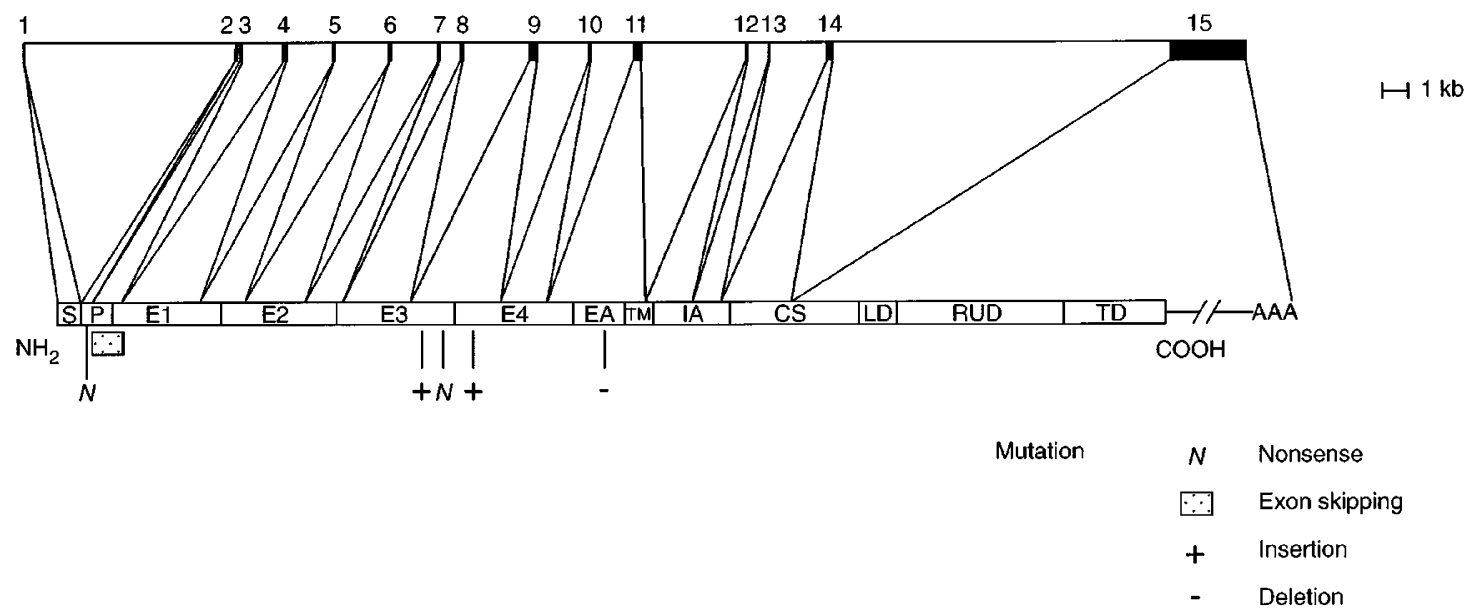

Figure 1 Diagram of the DSG1 gene and Dsg1 polypeptide and mutations identified in patients with SPPK. The size and position of the exons are shown relative to the gene and polypeptide. S represents the signal sequence; $\mathrm{P}$, the pro-sequence; E1, E2. E3 and E4 are the 4 extracellular cadherin repeats; EA, the extracellular anchor domain; TM, the transmembrane domain; IA, the intracellular anchor domain; CS, the intracellular cadherin-like sequence; LD, proline-rich linker domain; RUD, desmoglein-specific repeat unit domain; TD, terminal domain.

\section{Mutation analysis}

The coding portion and intron-exon boundaries of the human DSG1 gene from five unrelated cases of SPPK (of Caucasian, European origin) were amplified by PCR and the PCR products were sequenced. One of these cases (case B) was a member of the original German family in the study first describing the linkage of this disease to markers close to the desmosomal cadherin locus on chromosome $18 \mathrm{q} 12.1 .^{6}$ Of the other three cases, in one (case C), there was no detectable linkage to polymorphic markers on chromosome 6 where the desmoplakin gene is located, this being the other gene in which mutations have been found giving rise to SPPK, and of three other cases where linkage data was not available (cases D, E and F), sequence analysis had not detected mutations in the desmoplakin gene in $\mathrm{E}$ and $\mathrm{F}$.

Sequence analysis of exon-derived PCR products revealed heterozygotic base changes in the genomic DNA of DSG1 from these five cases (see Figure 2 for case C), which were subsequently confirmed by the sequencing of at least six clones derived from each PCR product. Mutations were found in the following exons: exon 2 (case $\mathrm{C}$ ), exon 9 (cases $\mathrm{B}, \mathrm{E}$ and F) and exon 11 (case D), all of which code for extracellular parts of the desmoglein protein (Figure 1). The actual base changes are detailed in Table 3. All of the mutations examined resulted in truncated proteins, either because of nonsense mutations or frameshifts resulting from nucleotide addition or deletion. To ensure that none of these mutations were in fact polymorphisms, a panel of 50 unrelated unaffected individuals (100 chromosomes) of similar racial extraction were screened for the mutations by sequence analysis of PCR products, and none of the nucleotide changes were found other than in the cases detailed.

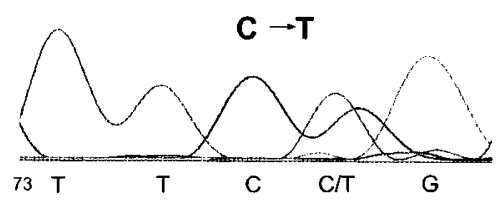

SPPK Heterozgous

DSG1

Exon 2

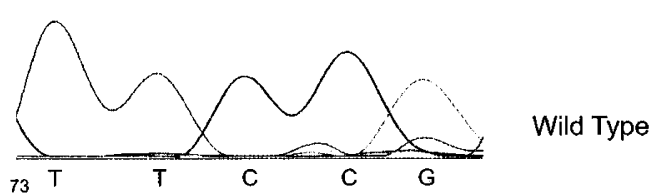

Figure 2 Automated DNA electropherogram of PCR-amplified genomic DNA from exon 2 of DSG1 from case $C$ using primers DS38 and DS37 showing the C to T transition at nt 76 as a heterozygote together with the wild-type homozygous sequence.

\section{Discussion}

Cadherins typically have five extracellular repeats that contain $\mathrm{Ca}^{2+}$-binding sites, a single transmembrane region and a cytoplasmic domain which contains binding sites for the various plaque proteins, plakoglobin, desmoplakin, plakophilin 1 and plakophilin 2. ${ }^{2}$ Both of the desmosomal cadherins, the desmogleins and desmocollins, resemble the classical cadherins in this general structure. The desmogleins differ from classical cadherins in having an extra region at their carboxy termini made up of a varying number, depending on the desmoglein type, of unique repeats. ${ }^{21}$ Both the desmocollins and the desmogleins are present as three isoforms, each of which have characteristic expression patterns both within an epithelium like the epidermis and 
Table 3 SPPK cases with mutations in the DSG1 gene

\begin{tabular}{lllllll}
\hline Case & Inheritance & Location & Mutation $^{a}$ & Nucleotide change $^{b}$ & Consequence & Protein domain \\
\hline A $^{c}$ & familial & exon 2 & IVS2-1G $>$ A & agGTA $\rightarrow$ aaGTA & in-frame exon skipping, exon 2 to 4 & prosequence (P) \\
B & familial & exon 9 & 1079 insC & CATTCA $\rightarrow$ CATTCCA & frameshift (PTC+6aa) & extracellular domain 3 (E3) \\
C & sporadic & exon 2 & 76C $>$ T R26X & TTCCGA $\rightarrow$ TTCTGA & nonsense & prosequence (P) \\
D & familial & exon 11 & 1627 delA & GACAAT $\rightarrow$ GACAT & frameshift (PTC+18aa) & extracellular anchor domain (EA) \\
E & familial & exon 9 & $1095 T>$ A Y365X & TATAAA $\rightarrow$ TAAAAA & nonsense & extracellular domain 3 (EC3) \\
F & unknown & exon 9 & 1189 delA & GGTAAT $\rightarrow$ GGTAT & frameshift (PTC+11aa) & extracellular domain 4 (EC4) \\
\hline
\end{tabular}

${ }^{\mathrm{a} N u m b e r i n g}$ of the amino acids refers to the human DSG1 peptide sequence. ${ }^{\mathrm{b}}$ Numbering of the nucleotides refers to the human DSG1 cDNA sequence (EMBL X56654) in which the ATG coding for methionine at nt 78 in the sequence ATGGACTGG is presumed to be the initiation codon, with the first nucleotide of this ATG codon as 1. Bases in exons are denoted by uppercase letters; bases in introns by lowercase letters;

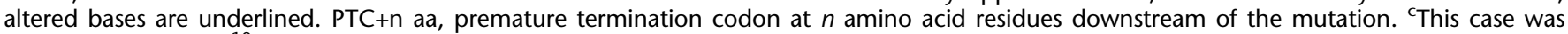
described previously. ${ }^{10}$

between different epithelial tissues. The type 2 isoforms have the widest tissue distribution. ${ }^{22,23}$ In contrast, type 1 and 3 isoforms have been detected only in certain stratified epithelia, the type 1 isoforms being expressed more suprabasally than the type 3 , DSC1 especially being restricted to the epidermis. ${ }^{24-27}$ The genes coding for the desmocollins (DSC) and the desmogleins (DSG), six in total, have been shown to be closely linked on human chromosome $18 \mathrm{q} 12.1^{7,28-31}$ in two tandem arrays, one of desmocollins, the other of desmogleins. ${ }^{13,32,33}$ Transcription occurs outwards from the region between the two arrays, and to some extent the gene order is correlated with the spatial order of gene expression during morphogenesis. ${ }^{34}$

When the strong cell-cell adhesion provided by the desmosomal cadherins is perturbed the consequences can be very serious. Thus in the human autoimmune skin diseases pemphigus foliaceous (PF) and pemphigus vulgaris (PV) where the respective autoantigens are Dsg1 and Dsg3, severe areas of blistering and cell separation (acantholysis) can, in the case of PV, be life-threatening. ${ }^{35}$ Recessive mutations in the plaque protein plakophilin 1 result in a severe ectodermal dysplasia/fragile skin syndrome. ${ }^{36-38}$ More indirectly affecting desmosome function, in the autosomal dominant skin diseases Darier's disease and Hailey-Hailey disease, where there is loss of adhesion between epidermal cells perhaps related to the observed loss of desmosomes caused by mutation either in ATP2A2 or ATP2C1 encoding calcium pumps, the resulting skin phenotype can be severe including widespread itchy crusted plaques, painful erosions and blistering. ${ }^{39-41}$ The desmoglein and desmocollin genes are also candidate tumour suppressor genes; loss of heterozygosity has been observed for a region of chromosome 18 including 18q12.1 in squamous cell carcinomas, ${ }^{42}$ and adhesion mediated by desmosomal cadherins in transfected and normally non-adhesive fibroblasts has been shown to be involved in inhibiting the invasiveness of these cells. ${ }^{43}$

In contrast to the loss of desmosomal function in pemphigus, striate palmoplantar keratoderma does not exhibit a widespread or particularly severe phenotype. Acantholysis, as seen in pemphigus, is not observed, nor are the blisters associated with the epidermolysis bullosa group of disorders which have defects in keratin filaments leading to cell fragility. ${ }^{44}$ Hyperkeratotic lesions are presumed to be restricted to those regions of the body where pressure and abrasion are greatest and where desmosome function is most necessary, so that SPPK provides a very sensitive measure of correct desmosome function. The first SPPK case described at the desmosomal cadherin locus at $18 \mathrm{q} 12.1^{10}$ was a mutation in the splice donor site in intron 2 and resulted in aberrant splicing of exon 2 to exon 4 with the consequent removal of exon 3 encoding part of the prosequence, the mature protein cleavage site and part of the first extracellular domain. The mutant allele was however still transcribed and thus it was difficult to decide whether dominance was due to the effects of the mutant protein, either disrupting desmosome structure or sequestering cytoplasmic proteins, or because of haploinsufficiency. All of the new mutations described in the present study would cause truncated proteins, either because of nonsense mutations resulting in stop codons or additions or deletions of nucleotides resulting in frame-shifts and premature termination downstream. All of the mutations were in the extracellular domain of the protein with a preponderance in exon 9. Interestingly the mutation in case $\mathrm{C}$ introduces a stop codon in exon 2 after only 25 amino acid residues of the pro-protein which, even if synthesised, would not be expected to interfere with mature protein function. Dominance of this mutation is most probably therefore due to haploinsufficiency of DSG1, ie loss of function is dominant to wild-type implying that diploid dosage is required for normal function. To our knowledge, haploinsufficiency of a cadherin has not previously been reported. It is possible that in some of the other cases, where a truncated polypeptide with a substantial amount of the extracellular domain could be synthesised, a dominant negative effect due to interaction of this polypeptide with desmosomes could be contributing to the dominance. Haploinsufficiency has also been implicated as the cause of autosomal dominance for SPPK caused by mutation in the desmoplakin gene. ${ }^{8,9}$

The reason for the preponderance of SPPK mutations in the DSG1 gene rather than in another desmosomal cadherin suggests that desmoglein 1 is a key protein in desmosome 
structure and function in the epidermis. Similarly although some cases of pemphigus have now been attributed to desmocollin autoantigens, ${ }^{45}$ nevertheless most pemphigus cases are due to autoimmunity involving Dsg1 and Dsg3. The desmogleins differ from the desmocollins in containing a region at their C-terminus made up of a number of unique repeats which is predicted to form an anti-parallel $\beta$-sheet and which can be visualised as a knob-like structure. ${ }^{46}$ Desmogleins may have a scaffolding role in the desmosome, for which there is some evidence from immunogold labelling experiments $^{1}$ (and IDJ Burdett, personal communication), in which its unique cytoplasmic structure may play a part, so that loss of desmoglein expression could have particularly crucial consequences for desmosome function.

\section{Electronic database information}

The five novel mutations have been submitted to the Human Gene Mutation Database (HGMD), http://link.springer.de/ journals/humangen/mutation/.

\section{Note added in proof}

The suggestion in the Discussion that desmoglein, in the upper layers of the skin specifically desmoglein 1 , is the key protein holding together the desmosome, has recently been borne out by the finding that the staphylococcal scalded-skin syndrome (SSSS) is caused by exfoliate toxin A produced by Staphylococcus aureus which cleaves this protein rather than one of the desmocollins (Amagai M, Matsuyoshi N, Wang N, Andl C, Stanley JR: Toxin in bullous impetigo and staphylococcal scalded-skin syndrome targets desmoglein 1. Nat Med 2000; 6: 1275-1277).

\section{Acknowledgments}

We thank the patients for their cooperation in this study. Drs Karen Harman, Jemima Mellerio and Claire Fuller (King's College Hospital) are thanked for their referral of case F. This work was supported by the Medical Research Council (DM Hunt, L Rickman, RS Buxton), the Wellcome Trust (HP Stevens, RAJ Eady, IM Leigh, DP Kelsell), the Deutsche Forschungsgemeinschaft (D Šmrak, J Arnemann, HC Henies), the Special Trustees of St Thomas' Hospital (NV Whittock, JA McGrath) and by a grant from the British-German Academic Research Collaboration to RS Buxton and J Arnemann. D Šimrak was also supported by an EMBO short-term fellowship and by a Wellcome Trust Travelling Fellowship. DKB Armstrong was supported by the British Skin Foundation.

\section{References}

1 Burdett IDJ: Aspects of the structure and assembly of desmosomes. Micron 1998; 29: 309-328.

2 Kowalczyk AP, Bornslaeger EA, Norvell SM, Palka HL, Green KJ: Desmosomes: intercellular adhesive junctions specialized for attachment of intermediate filaments. Int Rev Cytol 1999; 185: 237-302.

3 Schmidt A, Langbein L, Pratzel S, Rode M, Rackwitz HR, Franke WW: Plakophilin 3 - a novel cell-type-specific desmosomal plaque protein. Differentiation 1999; 64: 291-306.
4 Stevens HP, Kelsell DP, Bryant SP et al: Linkage of an American pedigree with palmoplantar keratoderma and malignancy (palmoplantar ectodermal dysplasia type III) to $17 q 24$. Literature survey and proposed updated classification of the keratodermas. Archives Dermatol 1996; 132: 640-651.

5 Kelsell DP, Stevens HP: The palmoplantar keratodermas: much more than palms and soles. Mol Med Today 1999; 5: 107-113.

6 Hennies H-C, Küster W, Mischke D, Reis A: Localization of a locus for the striated form of palmoplantar keratoderma to chromosome $18 \mathrm{q}$ near the desmosomal cadherin gene cluster. Hum Mol Genet 1995; 4: 1015-1020.

7 Arnemann J, Spurr NK, Wheeler GN, Parker AE, Buxton RS: Chromosomal assignment of the human genes coding for the major proteins of the desmosome junction, desmoglein DGI (DSG), desmocollins DGII/III (DSC), desmoplakins DPI/II (DSP), and plakoglobin DPIII (JUP). Genomics 1991; 10: 640-645.

8 Armstrong DKB, McKenna KE, Purkis PE et al: Haploinsufficiency of desmoplakin causes a striate subtype of palmoplantar keratoderma. Hum Mol Genet 1999; 8: 143-148.

9 Whittock NV, Ashton GHS, Dopping-Hepenstal PJC et al: Striate palmoplantar keratoderma resulting from desmoplakin haploinsufficiency. J Invest Dermatol 1999; 113: 940 - 946.

10 Rickman L, Simrak D, Stevens HP et al: Amino-terminal deletion in a desmosomal cadherin causes the autosomal dominant skin disease striate palmoplantar keratoderma. Hum Mol Genet 1999; 8: $971-976$.

11 Küster W, Hennies HC, Reis A: Keratosis palmoplantaris striata Brünauer-Fuhs-Siemens-klinische, lipidbiochemische und molekularbiologische Untersuchungen. Z Hautkr 1995; 70: $263-$ 268.

12 Sambrook J, Fritsch EF, Maniatis T: Molecular Cloning. A Laboratory Manual. Cold Spring Harbor, New York, Cold Spring Harbor Laboratory Press, 1989.

13 Hunt DM, Sahota VK, Taylor K et al: Clustered cadherin genes: a sequence-ready contig for the desmosomal cadherin locus on human chromosome 18. Genomics 1999; 62: 445-455.

14 Wheeler GN, Parker AE, Thomas CL et al: Desmosomal glycoprotein I, a component of intercellular desmosome junctions, is related to the cadherin family of cell adhesion molecules. Proc Natl Acad Sci USA 1991; 88: 4796-4800.

15 Ringwald M, Baribault H, Schmidt C, Kemler R: The structure of the gene coding for the mouse cell adhesion molecule uvomorulin. Nucleic Acids Res 1991; 19: 6533-6539.

16 Berx G, Staes K, Van Hengel J et al: Cloning and characterization of the human invasion suppressor gene E-cadherin (CDH1). Genomics 1995; 26: 281-289.

17 Wallis J, Fox MF, Walsh FS: Structure of the human N-cadherin gene: YAC analysis and fine chromosomal mapping to 18q11.2. Genomics 1994; 22: 172-179.

18 Puttagunta S, Mathur M, Cowin P: Structure of DSG1, the bovine desmosomal cadherin gene encoding the pemphigus foliaceus antigen - evidence of polymorphism. J Biol Chem 1994; 269: 1949 - 1955.

19 Silos SA, Tamai K, Li KH et al: Cloning of the gene for human pemphigus vulgaris antigen (desmoglein 3), a desmosomal cadherin. Characterization of the promoter region and identification of a keratinocyte-specific cis-element. J Biol Chem 1996; 271: $17504-17511$.

20 Greenwood MD, Marsden MD, Cowley CME, Sahota VK, Buxton RS: Exon-intron organization of the human type 2 desmocollin gene (DSC2): desmocollin gene structure is closer to 'classical' cadherins than to desmogleins. Genomics 1997; 44: 330-335.

21 Buxton RS, Magee AI: Structure and interactions of desmosomal and other cadherins. Semin Cell Biol 1992; 3: 157-167.

22 Nuber UA, Schäfer S, Schmidt A, Koch PJ, Franke WW: The widespread human desmocollin Dsc2 and tissue-specific patterns of synthesis of various desmocollin subtypes. Eur J Cell Biol 1995; 66: $69-74$. 
23 Schäfer S, Koch PJ, Franke WW: Identification of the ubiquitous human desmoglein, Dsg2, and the expression catalogue of the desmoglein subfamily of desmosomal cadherins. Exp Cell Res 1994; 211: 391 - 399 .

24 Arnemann J, Sullivan KH, Magee AI, King IA, Buxton RS Stratification-related expression of isoforms of the desmosomal cadherins in human epidermis. J Cell Sci 1993; 104: 741 - 750.

25 King IA, Sullivan KH, Bennett R, Buxton RS: The desmocollins of human foreskin epidermis: identification and chromosomal assignment of a third gene and expression patterns of the three isoforms. J Invest Dermatol 1995; 105: 314-321.

26 Adams MJ, Reichel M, King IA et al: Characterization of the regulatory regions in the human desmoglein genes encoding the pemphigus foliaceous and pemphigus vulgaris antigens. Biochem J 1998; 329: 165 -174.

27 King IA, O'Brien TJ, Buxton RS: Expression of the 'skin-type' desmosomal cadherin DSC1 is closely linked to the keratinization of epithelial tissues during mouse development. I Invest Dermatol 1996; 107: 531 - 538.

28 Arnemann J, Spurr NK, Magee AI, Buxton RS: The human gene (DSG2) coding for HDGC, a second member of the desmoglein subfamily of the desmosomal cadherins, is, like DSG1 coding for desmoglein DGI, assigned to chromosome 18. Genomics 1992 ; 13: $484-486$.

29 Arnemann J, Spurr NK, Buxton RS: The human gene (DSG3) coding for the pemphigus vulgaris antigen is, like the genes coding for the other two known desmogleins, assigned to chromosome 18. Hum Genet 1992; 89: 347 - 350.

30 Amagai M, Wang YM, Minoshima S et al: Assignment of the human genes for desmocollin 3 (DSC3) and desmocollin 4 (DSC4) to chromosome 18q12. Genomics 1995; 25: 330-332.

31 Wang YM, Amagai M, Minoshima S et al: The human genes for desmogleins (Dsg1 and Dsg3) are located in a small region on chromosome 18q12. Genomics 1994; 20: 492-495.

32 Simrak D, Cowley CME, Buxton RS, Arnemann J: Tandem arrangement of the closely linked desmoglein genes on human chromosome 18. Genomics 1995; 25: 591-594.

33 Cowley CME, Simrak D, Marsden MD, King IA, Arnemann J, Buxton RS: A YAC contig joining the desmoglein and desmocollin loci on human chromosome 18 and ordering of the desmocollin genes. Genomics 1997; 42: 208-217.

34 King IA, Angst BD, Hunt DM, Krüger M, Arnemann J, Buxton RS: Hierarchical expression of desmosomal cadherins during stratified epithelial morphogenesis in the mouse. Differentiation 1997; 62: 83-96.
35 Stanley JR: Cell adhesion molecules as targets of autoantibodies in pemphigus and pemphigoid, bullous diseases due to defective epidermal cell adhesion. Advan Immunol 1993; 53: $291-325$.

36 McGrath JA, McMillan JR, Shemanko CS et al: Mutations in the plakophilin 1 gene result in ectodermal dysplasia/skin fragility syndrome. Nat Genet 1997; 17: 240-244.

37 McGrath JA, Hoeger PH, Christiano AM et al: Skin fragility and hypohidrotic ectodermal dysplasia resulting from ablation of plakophilin 1. Br J Dermatol 1999; 140: 297 - 307.

38 McGrath JA: Hereditary disorders of desmosomes. J Dermatol Sci 1999; 20: 85 - 91

39 Sakuntabhai A, Ruiz-Perez V, Carter S et al: Mutations in ATP2A2, encoding a Ca2+ pump, cause Darier disease. Nat Genet 1999; $21: 271-277$.

$40 \mathrm{Hu}$ ZL, Bonifas JM, Beech J et al: Mutations in ATP2C1, encoding a calcium pump, cause Hailey-Hailey disease. Nat Genet 2000; 24: $61-65$.

41 Sudbrak R, Brown J, Dobson-Stone C et al: Hailey-Hailey disease is caused by mutations in ATP2C1 encoding a novel Ca(2+) pump. Hum Mol Genet 2000; 9: 1131 - 1140.

42 Jones JW, Raval JR, Beals TF et al: Frequent loss of heterozygosity on chromosome arm $18 \mathrm{q}$ in squamous cell carcimomas. Identification of 2 regions of loss - 18q11.1-q12.3 and 18q21.1-q23. Arch Otolaryngol Head Neck Surg 1997; 123: 610_ 614.

43 Tselepis C, Chidgey M, North A, Garrod D: Desmosomal adhesion inhibits invasive behavior. Proc Natl Acad Sci USA 1998; 95: 8064-8069.

44 Corden LD, McLean WHI: Human keratin diseases: hereditary fragility of specific epithelial tissues. Exp Dermatol 1996; 5: 297 307.

45 Hashimoto T, Kiyokawa C, Mori O et al: Human desmocollin 1 (Dsc1) is an autoantigen for the subcorneal pustular dermatosis type of IgA pemphigus. J Invest Dermatol 1997; 109: 127-131.

46 Rutman AJ, Buxton RS, Burdett IDJ: Visualisation by electron microscopy of the unique part of the cytoplasmic domain of a desmoglein, a cadherin-like protein of the desmosome type of cell junction. FEBS Lett 1994; 353: 194-196. 